\title{
The Impact of Mental Computation on Children's Mathematical Communication, Problem Solving, Reasoning, and Algebraic Thinking
}

\author{
By Roland Pourdavood ${ }^{*}$, Kathy McCarthy ${ }^{\dagger}$ \& \\ Tess McCafferty
}

\begin{abstract}
Moving from arithmetic to algebraic thinking at early grades is foundational in the study of number patterns and number relationships. This qualitative study investigates mental computational activity in a third grade classroom's and its relationship to algebraic thinking and reasoning. The data sources include classroom observations, field notes, students' verbal and written communications, and interviews. The study occurs in two phases; phase one includes establishing roles, rules, and expectations regarding how to talk about mathematical ideas; and phase two involves creating a classroom community that encourages participation, active listening, students' voices, and multiple perspectives. The findings of the study suggest that students' verbal communication enhances their problem-solving, reasoning, and communication. In addition, the findings suggest that creating learning opportunities for all students to do sophisticated mathematics requires competent and caring teachers who know their students' backgrounds, who understand the subject, and have strong pedagogical knowledge.
\end{abstract}

Keywords: algebraic reasoning, communication, children's mathematical thinking, mental computation.

\section{Introduction}

Mental computation refers to the process of working on a problem in one's head and obtaining the exact or approximate answers mentally, without the use of paper, a calculator, or other means (Jordan, Glutting, \& Ramineni 2010; Heirdsfield, 2011). Mental computation is important for children to learn, but the focus should not be limited to helping children develop mental computation strategies, but also to develop higher order thinking, reasoning, and critiquing, along with the ability to make sense of numbers and number operations (Carvalho \& da Ponte 2013; Erdem \& Gurbuz, 2015; Erdem, Gurbuz, \& Duran, 2011). It is an important thinking process because it enables children to: learn more in depth about how numbers relate to each other, make decisions about procedures, and create strategies for calculating (Tsao, 2011; Everett, Harsy, Hupp, \& Jewell, 2014). Mental computation is the most common form of computation used in everyday life. It is used for quick calculations and estimations, but is more than

${ }^{*}$ Professor, Cleveland State University, USA.

†Third Grade Teacher, Campus International School' USA.

"Third Grade Teacher, Campus International School' USA. 
mental arithmetic. When calculating mentally, students select from a range of strategies depending on the presenting problem (Bacon, 2012). As they develop their repertoire of strategies, students select those that are more efficient and effective for them. These thinking processes provide learners opportunities to construct relational understanding and algebraic thinking (O'Nan, 2003; Parrish, 2010, 2011; Obersteiner, Reiss, \& Ufer, 2013; Morin, 2017).

Algebra has been considered advanced mathematics for centuries and is typically taught in early middle school in the United States with the rationale being that middle school students have already mastered fundamental arithmetic and are prepared to use their cumulative acquired knowledge in mathematics towards algebraic concepts (Katz \& Parshall, 2014; Pyke \& LeFevre, 2011). Research has informed academia of the advantages of introducing algebraic thinking in early elementary years to foster a formidable learning of vital mathematics concepts in which children can then understand and apply to their future education (Gargiulo \& Metcalf, 2013).

The National Council of Teachers of Mathematics (NCTM, 2000) supports early algebra instruction to promote a foundation of principles and thought processes that will enrich analytical skills throughout life (Knuth, Stephens, Blanton, \& Gardiner, 2016). Algebraic thinking permeates through the fields of study of mathematics and is represented in the branches of science, technology and engineering. Algebra is a way of understanding the parts of which make up a whole and how relationships construct meaning. As the United States pushes to improve students' overall performance in mathematics, the focus of how to fundamentally improve the public school system of teaching mathematics has been targeted.

The intention of this research study is to investigate the relationship between children's mental mathematics and mathematical reasoning. The research question is: How do daily mental computations impact children's mathematical reasoning and algebraic thinking? In what follows, we present a review of literature followed by the philosophical and theoretical assumptions of the study. Then the context of the study, design of the study, and the methodology are discussed. In the next section, we discuss the results of the study and the final section of the paper focuses on the discussions and the significance of the study.

\section{Literature Review}

Building a repertoire of mathematical reasoning is a long and arduous process but it is one that benefits students' future understandings of mathematical patterns and relationships. The logic of algebra and the basic understanding of the equal sign can impact a student's mathematical path into the future. Providing students with the ability to analyze mathematical relationships in terms of comparable quantities and pattern detection while understanding the function of an equal sign gives them the tools to be successful in more advanced mathematics. Knuth, Stephens, Blanton and Gardiner (2016) investigated a longitudinal study on the impact of early algebraic thinking on third and fifth grade students' success in later 
school years. Their study, Early Algebraic Learning Progression (LEAP), found that students who received fundamental instruction in algebraic thinking throughout the early grades, demonstrated stronger ability and skills in factors such as the relations of the "equal sign, the function of variables, and the properties of variables in equations" (Knuth, et al, 2016, p. 68).

Similarly, Molina, Castro, and Ambrose (2005) examined how third grade students responded to an introduction to algebraic number sentences over the course of five separate lessons. The study focused on developing relational thinking about the equal sign and identifying patterns in number sentences. Students exhibited understanding by answering true/false number sentences and verbalizing explanations of pattern recognition. Although, due to the small sample size of their study, results of the study were limited; the findings of the study supported interpretations of similar studies (Knuth et al., 2016; Fuchs et al., 2008; Kiziltoprak \& Kose, 2017).

In a random sample from 789 second grade students, Powell and Fuchs (2014) compared students with mathematics difficulties in two different areas. They identified the two areas of focus as calculation and word-problem difficulties, in this study that spanned across 12 schools. Powell and Fuchs (2014) found that students who exhibited more challenges with word problems were less prepared for algebraic thinking. These findings also reinforce that students are capable of learning the fundamentals of algebraic thinking and that with additional instruction, students with mathematics difficulties could do better in advanced mathematics in the future. Further, calculation difficulties in early years could be remedied more seamlessly than word problem difficulties. In an earlier study, Fuchs et al. (2008) examined a sample of 89, third-grade classrooms to measure mathematical competence in computation and problem solving. Their findings were consistent with other research studies in that problem solving showed a stronger indication of mathematical encumbrance in algebraic thinking than that of computational challenges.

Congruent interpretations were found by Hart, Petrill, Thompson, and Plomin (2009) when they conducted a longitudinal study of 314 sets of twins in the United States, which assessed "cognitive ability, along with a myriad of mathematical ability in calculation, fluency, problem solving, and mathematical knowledge" (p. 5). Their testing extended into literacy abilities, as well as mathematical comprehension. The study found that word problem deficiencies were directly related to reading and mathematics skills, whereas calculation errors, were not found to have a correspondence with literacy or cognitive abilities.

In a qualitative study, Kiziltoprak and Kose (2017) met with six students in the fifth- grade on eight occasions to examine their "development of relational thinking" (p. 131). The researchers found that "even though [algebra] is first taught in secondary school years, importance should be given to the development of skills and concepts that will facilitate transition to algebra via student experiences and in-class discussions in early stages" (p. 131). They go on to define relational thinking as discerning the relationships between quantities with less concern on the final outcome or answer, but on the understanding the thought process to arrive 
at the answer based on the most logical relationship. They argue that arithmetic negates establishing relationships and therefore omits opportunities for deeper thinking processes to promote mathematical understanding, as in algebra. Rather, arithmetic is taught as an obscure and narrow sighted thought about one skill at a time. Their findings led them to recommend professional development programs for elementary teachers to incorporate relational thinking and number sense into their instructional approach in mathematics.

Since there is a close relationship between teachers' epistemology on how students learn mathematics and the way they teach it, a single most important factor for transforming the culture of mathematics classrooms is the epistemological change teachers must make on how students learn mathematics. Teachers become more aware of their instructional limitations and are more willing to re-examine their own methods and strategies through reflections on their own teaching and on their students' learning. Hofer and Pintrich (1997) assert that "beliefs about learning and teaching are related to how knowledge is acquired" (p. 116). Similarly, Cobb, Wood, and Yackel (1990) demonstrate how a secondgrade teacher integrated affective practices into her mathematics instruction. They state that the classroom teacher's self-reflections on her teaching and her students' learning; her interactions with the researchers; and her active collaboration with her colleagues; were primarily responsible for her epistemological transformation. The classroom teacher promoted independent problem-solving to strengthen student autonomy. The researchers suggest that establishing classroom social norms and clearly communicating expectations regarding the teacher's role and students' role in a mathematics classroom were crucial for creating learning opportunities for all students. In addition, they argue that discussion on how to talk about mathematical ideas, and what constitutes as a viable solution is a significant step toward creating a safe and caring learning community. Building a relationship with students is an important attribute for transforming and sustaining the culture of a mathematics classroom.

\section{Philosophical and Theoretical Assumptions}

The Philosophical and theoretical assumptions of this study is grounded in the Autopoiesis (Maturana, 1980, 1981, 1988) and Social Constructivist Epistemology (Cobb, 1994; Cobb, Wood, \& Yackel, 1990; Cobb \& Yackel, 1996). According to the Autopoiesis, living systems such as humans are structurally autonomous beings. It means they have their own individualities and their own identities. At the same time living beings are interactively open systems, which means they are capable of adapting themselves with new living environment. Maturana (1980; 1981; 1988) calls it structural coupling with the environment and with other beings. These structural couplings and interactions may facilitate, dis-equilibrate, and re-equilibrate one's ways of adaptation but these structural couplings cannot determine the direction and reconstruction of this adaptation. The process of adaptation is complex, non-linear, and probabilistic. Autopoiesis is consistent with Social Constructivist Epistemology (Cobb, 1994; Cobb, Wood, \& Yackel, 1990; Cobb \& Yackel, 1996). The Social Constructivist's perspective asserts that 
knowing and learning occur both individually and socially as the learner participates in and contributes to classroom activities. In this sense, knowing is inherently social and cultural activities. Autopoiesis and Social Constructivist Epistemology have significant pedagogical implications for transforming the traditional culture of teaching and learning mathematics.

The pedagogical approach tends to be presented either as teacher-centered or as students-centered, rather than exogenic and endogenic. Gergen (2001) presents these terms for educators to reflect on Piagetian theoretical foundations of accommodation and assimilation in the cognitive processes of students with regard to epistemological functioning. While Hofer and Pintrich (1997) contend Piaget prioritized ontogenesis, or individual development, Gergen (2001) posits that the foundation of epistemology lies in social relationships and through those social interactions knowledge is acquired. Therefore, students and teachers are in a position to enhance learning through social interaction and communicative practices that provide meaningful opportunities for multiple perspectives and multiple representations.

Mathematics instruction has traditionally been taught in a direct instruction approach where the teacher is the sole authority for validating the student's answer. In this traditional setting, usually the teacher asks a question followed by the student's response to the question, and teacher's evaluation of the response. The interaction between teacher and students is linear. In this teacher-centered mathematics classroom the emphasis is in the right answer rather than student's thinking process. The NCTM (1989, 1991, 1995, \& 2000) addresses the importance of problem solving, reasoning and proofs, mathematical communication, mathematical connection, and multiple representations. Similarly, Confrey (1990) insists students must construct ideas to grow their abilities and knowledge of mathematics across discipline, independent of rote memorization. This motivates students to take responsibility for their learning by "posing, constructing, exploring, solving and justifying mathematical problems and concepts...to develop in students the capacity to reflect on and evaluate the quality of their construction" (Confrey, 1990, p. 112). Breaking the cycle of traditional direct-instruction teaching method may be as simple as engaging teachers in mathematical problem-solving situations so that they can see how it works and reflect on their own pedagogical approaches and transform their epistemologies and practices. Encouraging teachers and students to deviate from direct-instruction methods empowers both to develop thought processes and solutions that may not have been otherwise accessible.

\section{Context of the Study, Research Design and Methodology}

The participants in this research study attend an urban school in a Midwestern state during the 2016-2017 school year. The school serves approximately 594 students in Kindergarten through eighth grade. All 34 participants in this action research project are third grade students; 18 boys and 16 girls. The students are in a single, shared classroom with two full-time teachers; both of them are members 
of the research team. Of the total students, 14 of the students receive gifted services while one student receives special education services.

The study occurred in two phases. The first phase of the study began at the start of the school year and ran until roughly the middle of the second quarter. The second phase of the study started around the middle of the second quarter and ended at the end of the school year. During the first phase, the classroom teachers communicated with the students regarding the rules, roles, and expectations. For example, the teachers communicated with their students how to talk about mathematics, how to listen to one another's ideas and perspectives, and how to challenge each other's solutions during the problem solving activities. Not all students actively participated during the first phase of the study. One of the goals during the second phase of the study was the classroom teachers to encourage more students' voices, multiple perspectives, and student dialogues. Another goal of the instruction was to create autonomous learners who could communicate their thinking and reasoning with confidence. The classroom teachers tried to create a classroom community where critical thinking could thrive and active listening was encouraged.

This qualitative, descriptive, and interpretive research is grounded in constructivist inquiry (Guba \& Lincoln, 1994; 1989; Lincoln \& Guba, 1985). The study is context-specific by focusing on one third-grade classroom. Data sources include students' notebooks, weekly mental computation quizzes, recorded classroom discussions and debates, the pre- and post-test data, students' reflections on their attitudes toward mathematics and mental computations, classroom observations, and field notes.. An important aspect of trustworthiness of data analysis outlined by Guba and Lincoln $(1994 ; 1989)$ is triangulation of data. In this study triangulation of data processes occurred in three ways. First, the two classroom teachers triangulated data on daily bases as they interacted with their students every day during their breaks and after school. Second, the primary researcher and the two classroom teachers triangulated data once a month for consistency and clarification of their understanding and interpretations. Third, the data were triangulated via ongoing conversation between the two classroom teachers and students before and after classroom activities as follow-up clarifications and modifications of students' understanding and interpretations. Data collection and data analysis occurred simultaneously using constant comparative analysis (Guba \& Lincoln, 1994; 1989; Lincoln \& Guba, 1985) for understanding and interpreting the impact of daily mental computations on the students' mathematical reasoning and algebraic thinking

\section{Results}

\section{First Phase of the Children's Mental Computations and Communication}

During the first phase of the study, the classroom teachers would begin the mathematics activity by giving an interesting and challenging mental computation problem for the students to solve. Then they would allow students time to think 
and respond verbally. They would encourage students' multiple perspectives and would make sure that the goals of planning were fulfilled (e.g. clear communication, reasoning, and viable solutions). While observing, the teachers would listen actively to students' multiple perspectives and would record their solutions on the board. After all perspectives were presented and recorded on the board, the teachers would invite students to communicate their solutions. Examples below demonstrate the students' mental mathematics activities during the first phase of the study. In this sample, "T" stands for the classroom teachers and "S" stands for the participating students.

T: [She wrote a subtraction problem on the board, 339 - 117. The teachers provided students a wait time to think and respond. Only four students participated by offering their solutions: 223, 236, 234, and 232. The teacher called a student by her name and asked her to present her solution verbally.]

T: $\quad$ S1, please tell us how you got your solution.

S1: $\quad$ I got 222.

T: $\quad$ How did you get it?

S1: Well, I subtracted 17 from 39 and I got 22. [The teacher recorded on the board what the student said verbally, $39-17=22$.] Then, I subtracted 100 from 300 and I got 200. [The teacher wrote on the board $300-100=200$ ]. Then I added 22 to 200 and I got 222. [The teacher recorded the solution on the board $200+22=222]$.

Some students were listening to the classroom conversation. However, not all of them were actively participating and contributing to the classroom activity. The three other students, who presented their solutions differently, accepted their peer's solution without any discussions. As the study evolved, the classroom teachers presented more challenging division problems with the intention of creating learning opportunities and more classroom interactions.

T: [She wrote on the board, 93/3. After the wait time she called students for their solutions.]

S1: I changed 93 to 60 and 33. Then I divided 60 by 3 and I got 20. Then I divided 33 by 3 and I got 11 . I added 20 plus 11 and I got 31 .

T: [She recorded the student's verbal solution on the board]. Very good, any other solution?

S2: I got 31 but I did it differently.

T: $\quad$ Tell us about your strategy.

S2: $\quad$ I changed 93 to 21 and 72 . I divided 21 by 3 and I got 7 . Then I divided 72 by 3 and I got 24 . I added 7 to 24 and I got 31 .

T: $\quad$ Very good, any other way that you solved the problem using different method? 
S3: $\quad$ I came up with the same answer but did it differently. I changed 93 to 90 and 3 . Then I divided 90 by 3 and I got 30 . I divided 3 by 3 and it is 1.30 plus 1 is 31 .

There are several important observations regarding the first phase of the classroom activities. First, although the classroom teachers encouraged all students for participation and contributions to the classroom mental mathematics activity, only three or four students were the main talkers and contributors of the activities. The rest of the students were passive recipients of the solution provided by a few students. Second, the main interactions were between the classroom teachers and three to four students. Interactions among students were not present during the first phase of the study. Third, the classroom teachers were the validators of the students' solutions. Dialogues among students were absent during this phase.

\section{Second Phase of the Children's Mental Computations and Communication}

As the study changed into its second phase, the classroom teachers used several new strategies for engaging more students in the classroom discussions. For example, they noticed that some students did not answer when prompted with mental mathematics problems. Through conversations with the students, the classroom teachers determined not all felt proficient in their addition and subtraction. Because they were struggling with the basics, adding and subtracting mentally became a burden. The classroom teachers provided their students with opportunities for online practice, hoping this strategy would help some of their struggling students learn the basics. This strategy seemed to bridge some of the gaps students had in their computational knowledge. As students become more proficient in basic computation, they were more willing to take risks presenting their solutions during the classroom discussions. The classroom teachers also decided to add a weekly quiz to phase two for assessing their students' mathematical growth. In addition, during this phase, the classroom teachers spent extra time before and after school conferencing individually with students who were not able to work through problems. Furthermore, they used peer tutoring for those students who were potentially at risk. In what follows, we elaborate on a sample of the students' mental computations and communication during the second phase of the study.

T: [She wrote the problem on the board. 19 X 199. She waited for student to think mentally and then to verbalize their solutions.]

S1: $\quad$ I got 3,781.

T: How did you get it?

S1: Well, I added one to 199 and I got 200. [The classroom teacher recorded $199+1=200$.] Then I broke 19 to 10 and 9.200 times 10 is 2,000 . [The teacher is recording the student's solution strategy $200 \times 10=2,000$. All other students were actively listening and observing.] Then, I multiplied 200 by 9 and I got 1,800. [The teacher recorded 200 X $9=1,800$.] Then I added 2,000 and 1,800 and I got 3,800. [The teacher recorded exactly what 
the student said, $2,000+1,800=3,800$.] Then, I subtracted 19 from 3,800 and I got my answer 3,781. [The teacher wrote on the board 3,800 - $19=$ 3,781.]

T: $\quad$ Any questions? [Students were thinking.]

S2: Well, I got different answer. I got 3,782.

T: $\quad$ Tell us your strategy.

S2: $\quad$ I added one to 19 and changed it to 20. Then, I added one to 199 and changed it to 200. I multiplied 20 and 200 and I got 4,000. I subtracted 199 from 4,000 and I got 3,801. Then I subtracted 19 from 3,801 and I got 3,782. [The teacher recorded exactly what the student was communicating verbally. $19+1=20.199+1=200.200 \times 20=4,000.4,000-199=$ $3,801.3,801-19=3,782$.]

T: Now, we have two different solutions. What do you think? [She was asking the whole classroom community for their reflections and comments.]

S3: [He is looking at the S2 and communicating with him directly.] I think you need to subtract one from 3,782 to get to 3,781.

S2: But why? [S3 couldn't answer S2 question]

S4: $\quad$ Because S1 answer is 3,781 and your answer is 3,782, you need to subtract one from it to get your answer.

S2: I think my answer is correct. Why should I subtract one form it. [S4 couldn't challenge S2 either. The instructional time was almost over.\}

T: Obviously, we have differences of opinions. I think we are almost out of our instructional time. I would suggest we revisit this problem tomorrow. I would like you to think and come up with your clear explanation as to which one of these two solutions is correct.

In this episode of the classroom activity, several observations are important to note. First, the direction of the classroom communication shifted from teacherstudent communication to student-student communication and dialogues. Second, unlike the first phase of the study, the second phase illustrates the role of the classroom teachers as the facilitators and coaches rather than the dispensers of knowledge and the sole validators of students' solutions. Third, more students' participations and contributions to the classroom activities denote significant shift on the participating students' self-confidence and self-esteem. Fourth, the above episode demonstrates two sophisticated strategies from S1 and S2 for moving from arithmetic to algebraic thinking, namely, distributive properties of numbers. These ways of knowing and doing mathematics is foundation for further mathematical problem solving, reasoning, communication, and algebraic thinking.

The above two solution strategies presented by two students are traditionally known as FOIL Method. Without knowing the FOIL method, the two participating students presented their solutions to the arithmetical problem of 19 X 199 algebraically such as $(10+9)(200-1)$ or $(20-1)(200-1)$. Although, the students were not introduced to distributive properties of the numbers, and hence, were not able to defend their ideas in convincing ways, the classroom teachers 
acknowledged the students' thinking processes. They valued the virtues of not having figure out yet.

\section{Discussions}

We noticed several benefits of the classroom mental mathematics activities and communication. In general students became more comfortable with discussing their mathematical ideas, verbalizing their mathematical strategies, and providing each other mathematical supports when they were struggling with understanding various strategies during classroom discussions. As their knowledge about mathematical reasoning grew, students became comfortable challenging each other. Students also became more accepting of having more than one reasonable answer to a problem. It is important that children receive many opportunities to develop the skills and strategies associated with mental computations. Having number sense is necessary to understanding mathematical concepts, yet it is frequently lacking in many of today's elementary schools. Mental computation strategies help children develop higher order thinking, reasoning, critiquing, and making sense of number and number operations. Mental mathematics will not only serve students well in school but outside of the classroom as well. Students who master the strategies of mental mathematics will find that the strategy helps them in many situations.

Not all students will develop rapid mental mathematics to the same degree. Because of the students' different mathematical backgrounds and their different learning styles, some students may find their strength in mathematics through other avenues, such as visual or graphic representations when solving problems. No matter what strategies a student uses, mental mathematics has a clear place in school mathematics. The findings of the study suggest that the participating students developed a strong understanding of number patterns and number relationships. In addition, as they study evolved, the students became better problem solvers and better communicators. The levels of students' reasoning and argumentations significantly increased as they became more engaged in mathematical activities and gained more experience. In addition, their levels of social skills improved in terms of respecting one another's explanations. By actively listening to each other's solutions helped the students transforming themselves from passive recipients of the information to active participants. These achievements became actualized through competent and caring teachers who had both good content knowledge and strong pedagogical content knowledge. They created a classroom milieu conducive to learning mathematics. They trusted that all of their students could learn and do sophisticated mathematics if they were provided with adequate support mechanisms. 


\section{Concluding Remarks}

The verbal communication among students has multiple benefits. First, it encourages students to reflect and communicate their thinking and reasoning (e.g. meta-cognition) which promotes critical thinking practices. Second, as the students verbalize their solutions, these practices provide the classroom teachers opportunities to assess students understanding and as a result, enhance their learning. Third, the classroom dialogues compel the teachers to reflect on their teaching and inform their instructions.

In addition, the study is significant in two important ways. First, the notion of a caring community was present from the beginning of the study and it continued consistently throughout the school year. The classroom teachers knew their students' backgrounds and built strong relationships with them. They trusted that all of their students could learn mathematics. Second, the students trusted their teachers and valued mathematical problem solving, reasoning, and communication. The students provided each other support during their cooperative learning. They would ask each other for help when they needed it before asking their classroom teachers for help. Incorporating number talk in early elementary by stimulating algebraic thinking seems to foster a foundation for success in a student's future.

\section{References}

Bacon, A. (2012). Mathematical student motivation Online Submission. Retrieved from https://bit.ly/2HJGyG1.

Carvalho, R., \& da Ponte, J. P. (2013). Student's mental computation strategies with rational numbers represented as fractions. Paper presented at The Eighth Congress of European Research in Mathematics Education (CERME 8), Antalya.

Confrey, J. (1990). What constructivism implies for teaching. Journal for Research in Mathematics Education. Monograph, 4, 107-210. doi: 10.2307/749916.

Cobb, P. (1994, Oct.). Where is mind? Constructivist and sociocultural perspectives on mathematical development. Educational Researcher, 23(7), 13-20.

Cobb, P., \& Yachel, E. (1996). Constructivist, emergent, and sociocultural perspectives in the context of developmental research. Educational Psychologist, 31(3/4), 175-190.

Cobb, P., Wood, T., \& Yackel, E. (1990). Classroom as learning environments for teachers and researchers. Journal for Research in Mathematics Education, 4, 25-146.

Erdem, E., \& Gürbüz, R. (2015). An analysis of seventh-grade students' mathematical reasoning. Cukurova University Faculty of Education Journal, 45(1), 123-142.

Erdem, E., \& Gürbüz, R., \& Duran, H. (2011). An investigation of mathematics used in daily life from past to present: theory out practice in. Turkish Journal of Computer and Mathematics Education, 2, 232-246.

Everett, G.E., Harsy, J.D., Hupp, S.D.A., \& Jewell, J.D. (2014). An investigation of the look-ask-pick mnemonic to improve fraction skills. Education \& Treatment of Children, 37(3), 371-391.

Fuchs, L.S., Fuchs, D., Stuebing, K., Fletcher, J.M., Hamlett, C.L., \& Lambert, W. (2008). Problem solving and computational skill: Are they shared or distinct aspects of mathematical cognition? Journal of Educational Psychology, 100(1), 30-47. 
Gargiulo, R.M., \& Metcalf, D. (2013). Teaching in today's inclusive classrooms: A universal design for learning approach $\left(2^{\text {nd }}\right.$ ed.). Independence, KY: Cengage Learning.

Gergen, K.J. (2001). Social construction and pedagogical practice. Social Construction in Context, 115-136.

Guba, E.G., \& Lincoln, Y.S. (1994). Comparing paradigm in qualitative research. In N.K. Denzin \& Y.S. Lincoln (Eds.), Handbook of Qualitative Research (pp.105-117). Thousand Oaks, CA: Sage.

Guba, E.G., \& Lincoln, Y.S. (1989). Fourth generation evaluation. Newbury Park, CA: Sage.

Hart, S.A., Petrill, S.A., Thompson, L.A., \& Plomin, R. (2009). The ABCs of math: A genetic analysis of mathematics and its links with reading ability and general cognitive ability. Journal of Educational Psychology, 101, 388-402.

Heirdsfield, A.M. (2011). Teaching mental computation strategies in early mathematics. YC: Young Children, 66(2), 96-102.

Hofer, B.K., \& Pintrich, P.R. (1997). The development of epistemological theories: Beliefs about knowledge and knowing and their relation to learning. Review of Educational Research, 67(1), 88-140.

Jordan, N.C., Glutting, J., \& Ramineni, C. (2010). The importance of number sense to mathematics achievement in first and third grades. Learning and Individual Differences, 20(2), 82-88.

Katz, V.J., \& Parshall, K.H. (2014). Taming the unknown: A history of algebra from antiquity to the early twentieth century. Princeton, NJ: Princeton University Press.

Kiziltoprak, A., \& Köse, N.Y. (2017). Relational thinking: The bridge between arithmetic and algebra. International Electronic Journal of Elementary Education, 10(1), 131145. doi:10.26822/iejee.2017131893.

Knuth, E., Stephens, A., Blanton, M., \& Gardiner, A. (2016). Build an early foundation for algebra success. Phi Delta Kappan, 97(6), 65-68. https://bit.ly/2Ww4JeG.

Lincoln, Y.S., \& Guba, E.G. (1985). Naturalistic inquiry. Beverly Hills, CA: Sage.

Maturana, H.R. (1988). Reality: The search for objectivity or the quest for a compelling argument. The Irish Journal of Psychology, 9(1), 25-82.

Maturana, H.R. (1981). Autopoiesis. In M. Zeleny (Ed.), Autopoiesis: A theory of living organization (pp. 21-23). New York: Elsevie-North Holand.

Maturana, H.R. (1980). Introudaction and biology of cognition. In H.R. Maturana \& F.J. Varela, Atoupoiesis and cognition: The realization of the living (pp. xi-xxx, 5-58). Boston; D. Reidel Publishing Company.

Molina, M., Castro, E., \& Ambrose, R. (2005). Enriching arithmetic learning by promoting relational thinking. International Journal of Learning, 12(5), 265-270.

Morin, A. (2017). What is mental math? How is it used? Retrieved from https://bit.ly/2I3 D8xt.

National Council of Teachers of Mathematics. (2000). Principles and standards for school mathematics. Reston, VA: NCTM.

National Council of Teachers of Mathematics. (1995). Assessment standards for School mathematics. Reston, VA: NCTM.

National Council of Teachers of Mathematics. (1991). Professional standards for teaching mathematics. Reston, VA: NCTM.

National Council of Teachers of Mathematics. (1989). Curriculum and evaluation standards. Reston, VA: NCTM.

Obersteiner, A., Reiss, K., \& Ufer, S. (2013). How training on exact or approximate mental representations of number can enhance first-grade student's basic number 
processing and arithmetic skills. Learning and Instruction, 23, 125-135. doi:10.1016/ j.learninstruc.2012.08.004.

O'Nan, M.A. (2003). Daily number talks and the development of computational strategies in fourth graders. (Master's Thesis). Johnson Bible College, Tennessee. Retrieved from ERIC on April 21, 20127.

Parrish, S.D. (2011). Number talks build numerical reasoning. Teaching Children Mathematics, 18(3), 198-206.

Parrish, S.D. (2010). Number talks: Helping children build mental math and computation strategies. Sausalito, CA: Math Solutions.

Powell, S.R., \& Fuchs, L.S. (2014). Does early algebraic reasoning differ as a function of students' difficulty with calculations versus word problems?. Learning Disabilities Research \& Practice (Wiley-Blackwell), 29(3), 106-116. doi:10.1111/ldrp.12037

Pyke, A.A., \& LeFevre, J. (2011). Calculator use need not undermine direct-access ability: The roles of retrieval, calculation, and calculator use in the acquisition of arithmetic facts. Journal of Educational Psychology, 103(3), 607-616.

Tsao, Y. (2011). The study of number sense and teaching practice. Journal of Case Studies in Education, 2(1), 1-14. 
